\title{
Clinical trial research on COVID-19 in Germany - a systematic
}

\section{analysis [version 1; peer review: 1 approved]}

\author{
Julian Hirt(iD1,2, Abeelan Rasadurai (iD)3, Matthias Briel(D1,4, Pascal Düblin1, \\ Perrine Janiaud $^{1 *}$, Lars G. Hemkens ${ }^{1,5,6^{*}}$
}

\footnotetext{
${ }^{1}$ Department of Clinical Research, University Hospital Basel, University of Basel, Basel, Spitalstrasse 12, 4031 Basel, Switzerland 2International Graduate Academy, Institute for Health and Nursing Science, Medical Faculty, Martin Luther University HalleWittenberg, Magdeburger Strasse 8, 06112 Halle (Saale), Germany

${ }^{3}$ Department of Health Sciences and Technology, ETH Zürich, Universitätstrasse 2, 8092 Zurich, Switzerland

${ }^{4}$ Department of Health Research Methods, Evidence, and Impact, McMaster University, 1280 Main Street West, Hamilton L8S 4L8, Ontario, Canada

${ }^{5}$ Meta-Research Innovation Center at Stanford (METRICS), Stanford University, 1265 Welch Road, Stanford, California 94305, USA

${ }^{6}$ Meta-Research Innovation Center Berlin (METRIC-B), Berlin Institute of Health, Anna-Louisa-Karsch-Strasse 2, 10178 Berlin, Germany

${ }^{*}$ Equal contributors
}

V1 First published: 10 Sep 2021, 10:913

https://doi.org/10.12688/f1000research.55541.1

Latest published: 10 Sep 2021, 10:913

https://doi.org/10.12688/f1000research.55541.1

\begin{abstract}
Background: In 2020, the COVID-19 pandemic led to an unprecedented volume of almost 3,000 clinical trials registered worldwide. We aimed to describe the COVID-19 clinical trial research agenda in Germany during the first year of the pandemic. Methods: We identified randomized clinical trials assessing interventions to treat or prevent COVID-19 that were registered in 2020 and recruited or planned to recruit participants in Germany. We requested recruitment information from trial investigators as of April 2021. Results: In 2020, 65 trials were completely $(n=27)$ or partially $(n=38)$ conducted in Germany. Most trials investigated interventions to treat COVID-19 (86.2\%; 56/65), in hospitalized patients (67.7\%; 44/65), with industry funding $(53.8 \% ; 35 / 65)$. Few trials were completed $(21.5 \%$; $14 / 65)$. Overall, 187,179 participants were planned to be recruited $(20,696$ in Germany), with a median number of 106 German participants per trial (IQR 40 to 345). From the planned German participants, 13.4\% were recruited (median 15 per trial (IQR 0 to 44). Conclusions: The overall German contribution to the worldwide COVID-19 clinical trial research agenda was modest. Few trials delivered urgently needed evidence. Most trials did not meet recruitment goals. Evaluation and international comparison of the challenges for conducting clinical trials in Germany is needed.
\end{abstract}

\section{Keywords}

COVID-19, SARS-CoV-2, Randomized clinical trials, Germany

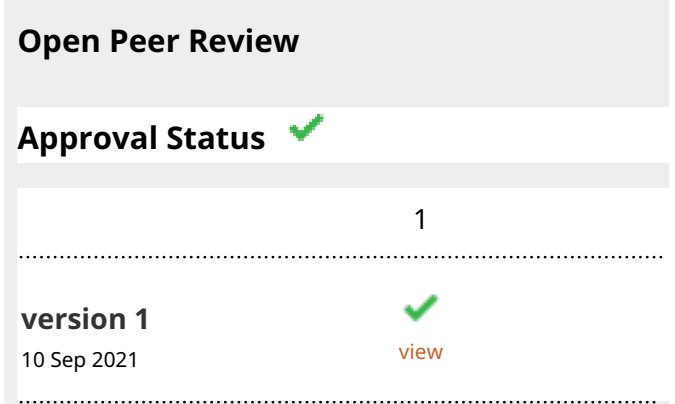

1. Anthony De Soyza, Newcastle University, Newcastle, UK National Institute for Health Research, Newcastle, UK

Any reports and responses or comments on the article can be found at the end of the article. 


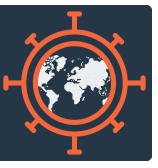

This article is included in the Emerging Diseases

and Outbreaks gateway.

collection.

\section{Corresponding author: Lars G. Hemkens (Lars.Hemkens@usb.ch)}

Author roles: Hirt J: Conceptualization, Formal Analysis, Investigation, Methodology, Project Administration, Software, Validation, Visualization, Writing - Original Draft Preparation, Writing - Review \& Editing; Rasadurai A: Investigation, Validation, Writing - Review \& Editing; Briel M: Investigation, Validation, Writing - Review \& Editing; Düblin P: Data Curation, Software, Writing - Review \& Editing; Janiaud P: Conceptualization, Formal Analysis, Investigation, Methodology, Project Administration, Software, Supervision, Validation, Visualization, Writing - Original Draft Preparation, Writing - Review \& Editing; Hemkens LG: Conceptualization, Funding Acquisition, Methodology, Project Administration, Resources, Supervision, Validation, Visualization, Writing - Original Draft Preparation, Writing Review \& Editing

Competing interests: No competing interests were disclosed.

Grant information: The COVID-evidence project is supported by the Swiss National Science Foundation, project ID 31CA30_196190. The funder had no influence on the design, conduct, results of this research nor its preparation and submission for publication.

The funders had no role in study design, data collection and analysis, decision to publish, or preparation of the manuscript.

Copyright: (c) 2021 Hirt J et al. This is an open access article distributed under the terms of the Creative Commons Attribution License, which permits unrestricted use, distribution, and reproduction in any medium, provided the original work is properly cited.

How to cite this article: Hirt J, Rasadurai A, Briel $\mathrm{M}$ et al. Clinical trial research on COVID-19 in Germany - a systematic analysis [version 1; peer review: 1 approved] F1000Research 2021, 10:913 https://doi.org/10.12688/f1000research.55541.1

First published: 10 Sep 2021, 10:913 https://doi.org/10.12688/f1000research.55541.1 


\section{Introduction}

The COVID-19 pandemic has led to an unprecedented volume and speed in the international clinical research agenda. Almost 700 clinical trials were registered worldwide in the first 100 days, which planned to recruit almost 400,000 participants to assess interventions to treat or prevent COVID-19. ${ }^{1}$ However, this research agenda has been tainted by a multitude of small trials with 50 from the 700 trials aimed to include more than 1,000 participants. ${ }^{1}$ Nevertheless, there were remarkable efforts to conduct large adaptive pragmatic trials directly informing therapeutic decisions in COVID-19 patients: the UK Randomised Evaluation of COVid-19 thERapY (RECOVERY) trial recruited 10,000 patients in two months, ${ }^{2}$ the established Randomised, Embedded, Multifactorial Adaptive Platform trial for Community-Acquired Pneumonia (REMAP-CAP) was rapidly adapted to COVID- $19,{ }^{3}$ and the COVID-19 Solidarity Trial for COVID-19 Treatments (SOLIDARITY) sponsored by the World Health Organization (WHO), was conducted in six months. ${ }^{4}$ In the first 100 days, China, the US, Spain and France, had the largest share of the initiated trials, with many planned as international collaborations. ${ }^{1}$ Germany contributed to large-scale international studies such as REMAP-CAP ${ }^{5}$ and WHOSOLIDARITY, ${ }^{6}$ and the German Federal Ministry for Education and Research (BMBF) provided 1.6 billion $€$ for COVID-19-related research. ${ }^{7}$

The aim of this study was to describe the German contribution to the worldwide COVID-19 clinical trial agenda, including all randomized clinical trials (RCTs) with German participants, that were registered during the first year of the pandemic.

\section{Methods}

Data sources

We searched the COVID-evidence database to identify RCTs in international trial registries (ClinicalTrials.gov; WHO International Clinical Trials Registry Platform). Additionally, we manually searched the German Clinical Trials Register (DRKS). For all eligible registered trials, we searched corresponding publication results and preprints in the Living OVerview of Evidence platform for COVID-19 (L·OVE), Cochrane COVID-19 Study Register, MEDLINE/PubMed, and Google Scholar using the trial registry number (last search 1 April 2021, see extended data ${ }^{8}$ ).

\section{Eligibility criteria}

We included all planned, ongoing, or completed RCTs assessing interventions to treat or prevent COVID-19, registered in 2020, that recruited or planned to recruit at least one participant in Germany.

\section{Selection of trials and data extraction}

One author $(\mathrm{JH})$ conducted the searches and screened the trials for eligibility and a second author (PJ or LGH) was consulted in cases where eligibility was unclear. Four authors (JH, PJ, AR, MB) extracted data on trial characteristics (status, duration, design, population, intervention and control, recruiting countries, actual/planned trial size, funding) and published results.

Trials with industrial/commercial sponsors were classified as industry-funded, those with public/non-commercial sponsors as public-funded, and trials with public/non-commercial sponsors with collaborators from industry as publicly funded with industry contribution. Trials were also classified as completely (i.e., national trials) or partially (i.e., international) conducted in Germany. Details on the extraction process are provided as extended data. ${ }^{8}$

\section{Recruitment information}

We identified contact details of corresponding investigators for all eligible trials using registry information and web search. For each trial, we asked investigators via email about the current trial status, inclusion date of the first patient, number of patients recruited in Germany, and any published results (prior to April 2021, see extended data ${ }^{8}$ ). For trials completely conducted in Germany with public funding, we further asked (i) if they were aware of other trials with public funding that we have not identified and (ii) to confirm the extracted information on their trial (see extended data ${ }^{8}$ ). We received replies from $60 \%$ (39 out of 65) of all eligible trials. This complemented the data contained in registries or publications and provided full information on actual and target sample size in Germany for 34 trials (52.3\%).

\section{COVID-evidence update}

COVID-evidence is a living database that is continuously being updated. ${ }^{9,10}$ Registry entries retrieved weekly from ClinicalTrials.gov and the WHO International Clinical Trials Registry Platform are automatically pre-screened for eligibility using basic filters to identify RCTs. Unclear and identified RCT entries are then manually screened to verify eligibility.

In August 2021, the RCT filter of COVID-evidence was updated. The data presented herein are based on the COVIDevidence processes (including RCT filter and automatic pre-screening) as of April 2021. For transparency and 
exhaustiveness, we updated our search in the COVID-evidence database in August 2021 with the use of the most recent processes and post-hoc identified trials.

Data analysis

We report medians with interquartile ranges (IQRs) if not stated otherwise. For all analyses, we used R (version 4.1).

\section{Results}

In 2020, 65 RCTs were planned to investigate treatments or preventive interventions for COVID-19 with participants from Germany (Table 1 and extended data ${ }^{8}$ ). They aimed to include a median of 300 participants per trial (IQR, 174 to 830) internationally, including 106 in Germany (IQR, 40 to 345, Table 2).

After a peak with 18 registrations in April 2020, one to nine trials were registered each month. As of 21 May 2021, 35 were ongoing (53.8\%), six not yet recruiting (9.2\%), nine terminated early (13.8\%), 14 (21.5\%) completed, and one withdrew and will never recruit $(1.5 \%)$.

Our results also indicate that 17 trials $(26.2 \%)$ had published results; 15 were partially conducted in Germany, 15 were explored COVID-19 therapies and 12 were industry-funded. From those 17 trials with published results, 12 trials had results published as peer-reviewed articles or preprints, and five trials had published results exclusively as press release or in the registry. Results were reported by 11 trials, while six stated interim results (Table 3 ).

Topic and design

From the 65 trials, 56 investigated COVID-19 therapies (86.2\%) with a total planned sample size of 33,540 participants internationally (median 256 per trial [IQR, 172 to 450]); seven (12.5\%) planned to recruit more than 1,000 participants.

Drugs and biologicals (e.g., convalescent plasma) were investigated in 48 of 65 trials $(73.8 \%)$. The spectrum of treatments was wide, including antivirals $(\mathrm{n}=10,20.8 \%$, e.g., remdesivir $\mathrm{n}=4)$, monoclonal antibodies $(\mathrm{n}=8,16.7 \%$, e.g., tocilizumab $n=3)$, convalescent plasma $(n=6,2.5 \%)$, hydroxychloroquine $(n=5,10.4 \%)$, and kinase inhibitors $(n=4$, $8.3 \%$, e.g., baricitinib $\mathrm{n}=1$ ).

All trials assessing interventions to prevent COVID-19 were vaccine trials (13.8\%; 9 from 65). They were considerably larger than therapy trials with a total planned sample size of 153,639 participants (median 2,520 per trial [IQR, 1,200 to $34,000]$ ); seven of the nine vaccine trials (77.7\%) planned to include over 1,000 participants. From the 187,179 planned participants in the 65 trials, $82.1 \%$ were healthy participants planned to be recruited in vaccine trials.

None of the trials investigated non-pharmaceutical interventions to prevent the pandemic spread, such as social distancing or behavioral interventions.

Hospitalized patients were recruited in 44 (67.7\%), outpatients in 14 (21.5\%), and both inpatients and outpatients in seven $(10.8 \%)$ trials. No trial was conducted in nursing homes, kindergarten, childcare, or schools (Table 1 and extended data ${ }^{8}$ ). Adolescents (12 years and older) were included in five trials partially conducted in Germany, however, trials that included children below the age of 12 did not exist.

Most trials were double blinded $(\mathrm{n}=36,55.4 \%)$ and used a two-arm parallel group design $(\mathrm{n}=54,83.1 \%)$. From the 11 trials that had an adaptive design $(17.0 \%)$, five re-estimated the target sample size.

\section{Funding and internationality}

From the 65 trials, 35 (53.8\%) were industry-funded, 25 (38.5\%) publicly funded, and five (7.7\%) publicly funded with industry contribution. None of the publicly funded trials assessed a vaccine (Table 4). In these 65 trials, 38 were partially conducted in Germany (58.5\%), which planned to recruit 172,782 participants across all included countries (median 402 per trial [IQR, 210 to 967]). Additionally, there were 27 trials completely conducted in Germany (41.5\%) that planned to recruit 14,397 participants (median 200 per trial [IQR, 103 to 500]) in 125 German study centers (median 1.5 centers per trial [IQR, 1 to 8.8$]$ ).

From the 38 trials partially conducted in Germany, nine (23.7\%) planned to recruit over 1,000 participants compared with five from $27(18.5 \%)$ of the trials that were completely conducted in Germany. 


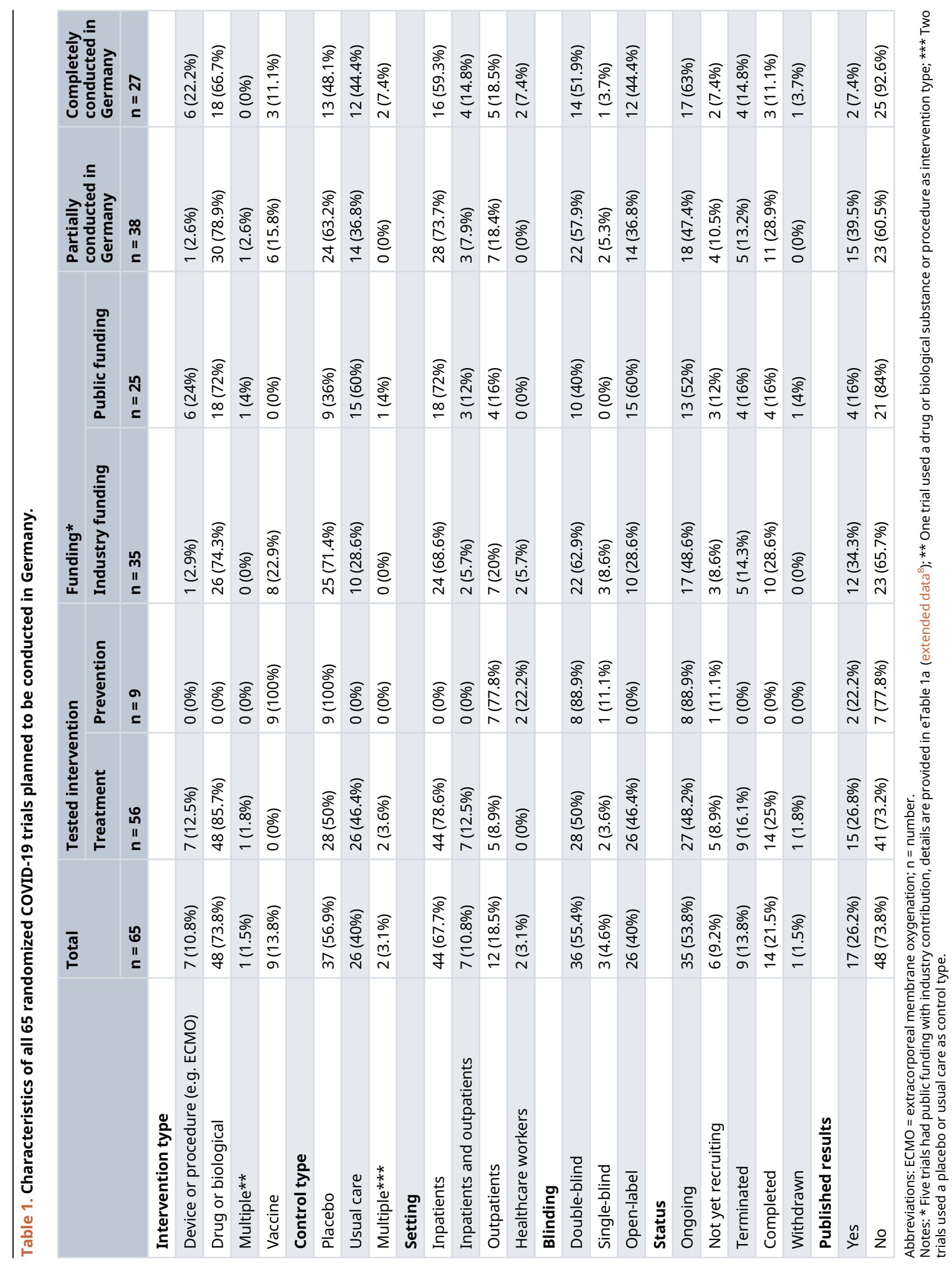




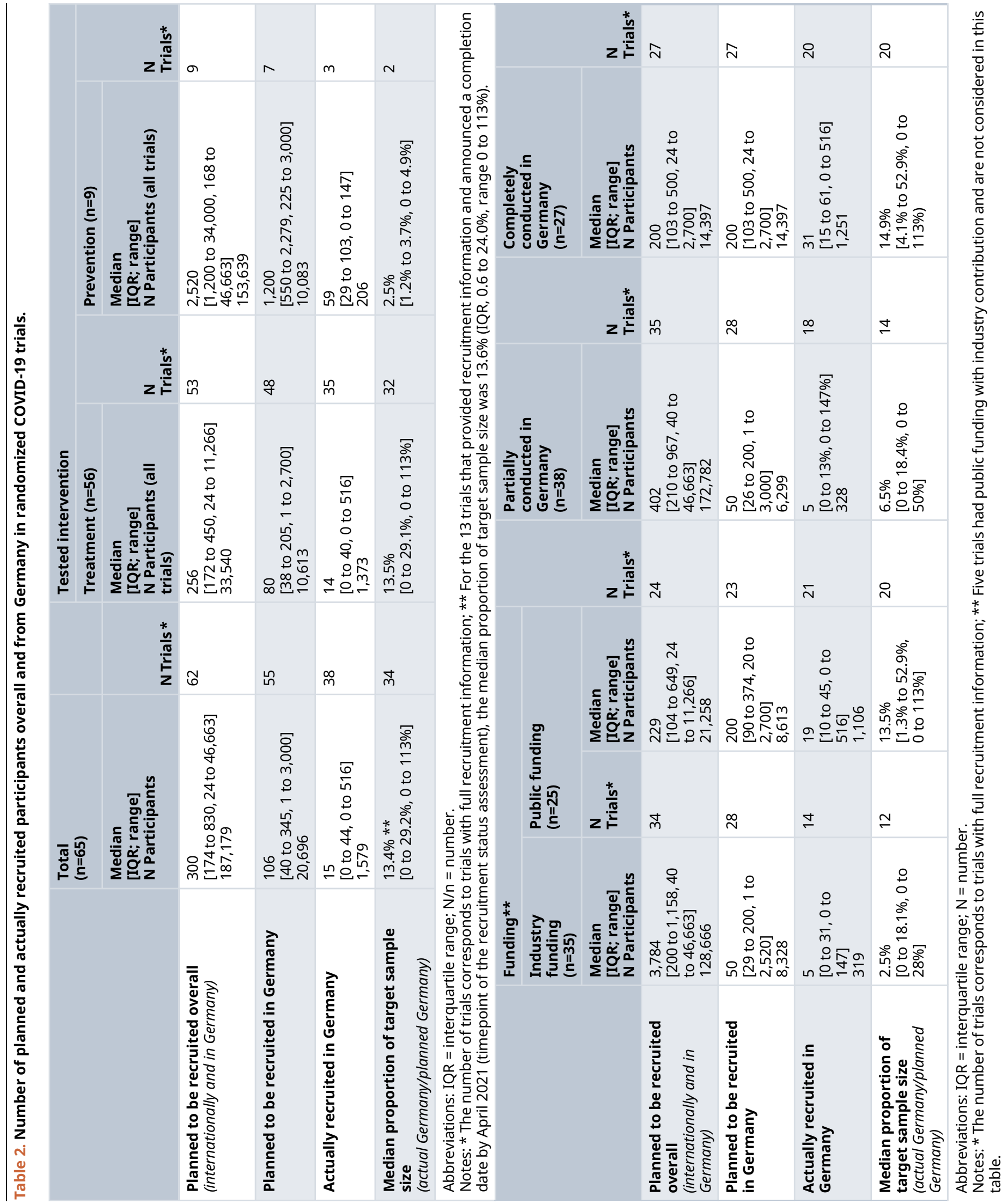


Table 3. Trial results summary and recruitment status of all 17 trials with published results.

\begin{tabular}{|l|l|}
\hline Trial acronym & Summary \\
\hline $\begin{array}{l}\text { GS-US-540-5773 } \\
\text { (NCT04292899) }\end{array}$ & $\begin{array}{l}\text { Remdesivir for } 5 \text { versus 10-days in hospitalized patients with severe } \\
\text { Covid-19 not requiring mechanical ventilation on clinical status at day } \\
14, \text { assessed on a 7-point ordinal scale. No stat. significant difference } \\
\text { between a 5-days and a 10-days course (65\% and 54\% patients, } \\
\text { respectively, showed a clinical improvement of at least } 2 \text { points } \\
\text { (p=0.14)). Results are based on } 402 \text { randomized patients. The trial was } \\
\text { then extended to include additional patients. } \\
\text { Results reported in a peer reviewed publication }\end{array}$ \\
& Clinicaltrials.gov (NCT04292899); industry-funded.
\end{tabular}

(NCT04333420)
GS-US-540-5774 (NCT04292730)

ACTT-1

(NCT04280705)

PANAMO

NCT04327388

(NCT02735707)

Remdesivir for 5 days or 10 days vs standard care in patients with moderate COVID-19 on clinical status at day 11, assessed on a 7-point ordinal scale. Patients randomized to 5 days remdesivir had a stat. significant benefit (odds ratio, $1.65,95 \% \mathrm{CI}[1.09 ; 2.48], \mathrm{p}=0.02$ ) but not those randomized to 10 days remdesivir $(p=0.18)$. Results are based on 596 randomized patients. The trial was then extended to include additional patients.

Results reported in a peer reviewed publication ${ }^{25}$ and posted on Clinicaltrials.gov (NCT04292730) and Clinicaltrialsregister.eu (EUCTR2020-000842-32-DE); industry-funded.

Remdesivir versus placebo in hospitalized patients with COVID-19 with evidence of lower respiratory tract infection on the time to recovery, defined by either discharge from the hospital or hospitalization for infection-control purposes only assessed on an 8-point ordinal scale. Remdesivir had a stat. significant benefit compared with placebo (rate ratio for recovery, 1.29, 95\% CI [1.12; 1.49], $\mathrm{p}<0.001$ ).

Results reported in a peer reviewed publication ${ }^{26}$ and posted on Clinicaltrialsregister.eu (EUCTR2020-001052-18-DE); industry-funded.

A phase 2/3 trial on anti-C5a antibody IFX-1 (vilobelimab) versus standard care in hospitalized patients with severe COVID-19 pneumonia on percentage change in $\mathrm{PaO}_{2} / \mathrm{FiO}_{2}$ in the supine position from baseline to day 5. Results focus on the phase 2 which randomized 30 patients in the Netherlands. No stat. significant difference for the percentage change in $\mathrm{PaO}_{2} / \mathrm{FiO}_{2}$ (difference $-24 \%, 95 \% \mathrm{CI}[-58 ; 9], \mathrm{p}=$ $0.15)$, but preliminary findings on mortality at 28-days promising enough to continue with phase 3 and mortality as primary endpoint. Results reported in a peer reviewed publication ${ }^{27}$; industry-funded.

COVACTA

(NCT04320615)

Tocilizumab versus standard of care in hospitalized patients with severe COVID-19 pneumonia on clinical status at day 28, assessed on a 7-point ordinal scale. No stat. significant difference for clinical status (betweengroup difference $-1.0,95 \%$ CI $[-2.5 ; 0] ; p=0.31$ ). Results reported in a peer reviewed publication ${ }^{28}$; public and industry funding.

Sarilumab (200 mg or $400 \mathrm{mg}$ ) versus placebo in hospitalized patients receiving supplemental oxygen with severe or critical COVID-19 on time to clinical improvement of two or more points on a 7-point ordinal scale. No stat. significant difference for time to clinical improvement $(200 \mathrm{mg}$ : HR $1.03,95 \%$ CI $[0.75 ; 1.4] ; p=0.96$ and $400 \mathrm{mg}$ : hazard ratio $1.14,95 \% \mathrm{CI}$ [0.84; 1.54], $p=0.34$ ).

Results reported in a peer reviewed publication ${ }^{29}$ and posted on Clinicaltrials.gov (NCT04327388); industry-funded.

Adaptive platform trial assessing multiple interventions in hospitalized patients with severe COVID-19 on an ordinal scale combining organ support-free days and in-hospital deaths at day 21. No stat. significant benefit on mortality for hydroxychloroquine (OR 1.04,95\% CI [0.49; 2.18]) assessed on 142 patients randomized. ${ }^{30}$

Treatment with a 7-day fixed-dose course of hydrocortisone or shockdependent dosing of hydrocortisone suggested a benefit assessed on 384 patients randomized. The intervention arms were terminated early following the press release from the RECOVERY trial showing a stat. significant benefit on mortality outcomes. ${ }^{31}$

Both tocilizumab and sarilumab (interleukin-6 receptor antagonists) met the predefined criteria for efficacy assessed on 803 patients randomized. ${ }^{32}$

\section{Actual/target sample size}

International: $4,838 / n . r$. Germany: 43/n.r.

International:

1,087/1,600

Germany: 37/200

International: 1,062/800

Germany: 13/100

International:

n.r./390

Germany: n.r./40

International:

452/450

Germany: n.r./50

International: 420/440

Germany: 6/25

International: 11,557/n.r. * Germany: n.r./ n.r. 
Table 3. Continued

\begin{tabular}{|c|c|c|}
\hline Trial acronym & Summary & $\begin{array}{l}\text { Actual/target } \\
\text { sample size }\end{array}$ \\
\hline & $\begin{array}{l}\text { Therapeutic anticoagulation did not improve hospital survival or days } \\
\text { free of organ support compared to usual care pharmacological } \\
\text { thromboprophylaxis assessed on } 1,074 \text { patients randomized. The } \\
\text { intervention arm was stopped for futility. } \\
\text { The convalescent plasma intervention arm reached a pre-specified } \\
\text { statistical threshold for futility among patients who are critically ill with } \\
\text { COVID-19. Although recruitment continued for moderate patients, } \\
\text { following the publication of the RECOVERY trial results showing no stat. } \\
\text { significant benefit on mortality outcomes the convalescent plasma } \\
\text { intervention arm was closed to recruitment. } \\
\text { Results reported in multiple peer reviewed publications, } \\
\text { preprints }^{33} \text { and press releases } \\
34,35 \\
\text {; industry-funded. }\end{array}$ & \\
\hline $\begin{array}{l}\text { EUCTR2020- } \\
\text { 001270-29-DE }\end{array}$ & $\begin{array}{l}\text { A phase } 2 / 3 \text { adaptive trial assessing hydroxychloroquine in hospitalized } \\
\text { patients with moderate to severe COVID-19 on changes from baseline } \\
\text { in oxygen saturation/fraction of inspired oxygen ratio at day } 15 \text {. The } \\
\text { trial was terminated early due to enrollment and feasibility challenges, } \\
\text { and due to evidence suggesting no benefit from hydroxychloroquine. } \\
\text { No statistical analysis was conducted due to the early termination of the } \\
\text { trial. } \\
\text { Results posted on Clinicaltrialsregister.eu (EUCTR2020-001270-29-DE); } \\
\text { industry-funded. }\end{array}$ & $\begin{array}{l}\text { International: } \\
\text { 14/350 } \\
\text { Germany: 0/80 }\end{array}$ \\
\hline $\begin{array}{l}\text { RUXCOVID } \\
\text { (NCT04362137) }\end{array}$ & 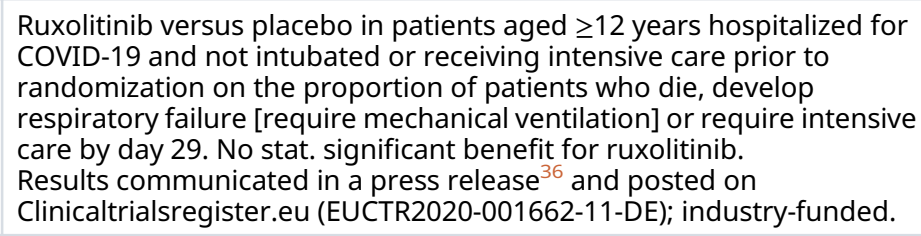 & $\begin{array}{l}\text { International: } \\
\text { 432/402 } \\
\text { Germany: 9/50 }\end{array}$ \\
\hline NCT04368728 & $\begin{array}{l}\text { Phase } 1 / 2 / 3 \text { assessing the safety, tolerability, immunogenicity, and } \\
\text { efficacy of RNA Vaccine Candidates (BNT162b2 - Pfizer-BioNTech) } \\
\text { against COVID-19. The ongoing phase } 3 \text { preliminary results showed } \\
\text { that a two-dose regimen of BNT162b2 conferred } 95 \% \text { protection } \\
\text { against Covid-19 in persons } 16 \text { years of age or older and the safety over } \\
\text { a median of } 2 \text { months was similar to that of other viral vaccines. } \\
\text { Results reported in multiple peer reviewed publications }{ }^{37-39} \text {; industry- } \\
\text { funded. }\end{array}$ & $\begin{array}{l}\text { International: } \\
\text { 43,548/46,663 } \\
\text { Germany: } \\
\text { n.r. } / 500\end{array}$ \\
\hline $\begin{array}{l}\text { Mir-Age } \\
\text { (NCT04393038) }\end{array}$ & $\begin{array}{l}\text { ABX464 versus placebo to treat inflammation and prevent acute } \\
\text { respiratory failure in high-risk patients with COVID-19 on the rate of } \\
\text { patients with no invasive or non-invasive mechanical ventilation. } \\
\text { Terminated early following the Data Safety and Monitoring Board } \\
\text { recommendation for lack of efficacy based on the interim analysis of } \\
305 \text { high-risk Covid-19 patients who completed the study period. No } \\
\text { quantitative data were reported. } \\
\text { Results communicated in a press release }{ }^{40} \text {; industry-funded. }\end{array}$ & $\begin{array}{l}\text { International: } \\
500 / 1,034 \\
\text { Germany: } \\
\text { n.r./200 }\end{array}$ \\
\hline $\begin{array}{l}\text { CAN-COVID } \\
\text { (NCT04382053) }\end{array}$ & $\begin{array}{l}\text { Canakinumab versus placebo in hospitalized patients with COVID-19 } \\
\text { pneumonia and cytokine release syndrome on survival without the } \\
\text { need for mechanical ventilation at day } 29 \text {. No stat. significant benefit } \\
\text { was shown for canakinumab ( } 88.8 \% \text { responders) versus placebo }(85.7 \% \\
\text { responders, } p=0.29) \text {. } \\
\text { Results communicated in a press release }{ }^{41} \text {; industry-funded. }\end{array}$ & $\begin{array}{l}\text { International: } \\
143 / 120 \\
\text { Germany: n.r./50 }\end{array}$ \\
\hline $\begin{array}{l}\text { COV-BARRIER } \\
\text { (NCT04421027) }\end{array}$ & $\begin{array}{l}\text { Baricitinib versus placebo in hospitalized patients with COVID-19 on the } \\
\text { composite endpoint percentage of participants who die or require non- } \\
\text { invasive ventilation/high-flow oxygen or invasive mechanical } \\
\text { ventilation at } 28 \text { days. No stat. significance for the primary endpoint (OR } \\
0.85,95 \% \mathrm{CI}[0.67 ; 1.08] \text { ) but data showed } 38 \% \text { reduction in mortality by } \\
\text { day } 28(p=0.0018) \text { in patients treated with baricitinib in addition to } \\
\text { standard of care including corticosteroids and remdesivir. } \\
\text { Results communicated in a press release }{ }^{42} \text {; industry-funded. }\end{array}$ & $\begin{array}{l}\text { International: } \\
\text { 1525/1400 } \\
\text { Germany: n.r./30 }\end{array}$ \\
\hline
\end{tabular}




\begin{tabular}{|c|c|c|}
\hline Trial acronym & Summary & $\begin{array}{l}\text { Actual/target } \\
\text { sample size }\end{array}$ \\
\hline $\begin{array}{l}\text { CureVac AG } \\
\text { (NCT04449276) }\end{array}$ & $\begin{array}{l}\text { Safety and immunogenicity profile after } 1 \text { and } 2 \text { dose administrations of } \\
\text { CVnCoV-vaccine at different dose levels in healthy adults. Interim } \\
\text { analysis of an ongoing phase } 1 \text { trial showed that two doses of CVnCoV } \\
\text { ranging from } 2 \mu \mathrm{g} \text { to } 12 \mu \mathrm{g} \text { per dose, administered } 28 \text { days apart were } \\
\text { safe and were able to boost the pre-existing immune response even at } \\
\text { low dose levels. This study allowed to select the } 12 \mu \mathrm{g} \text { dose for further } \\
\text { clinical investigation, including a phase } 2 \mathrm{~b} / 3 \text { study investigating } \\
\text { efficacy, safety, and immunogenicity of the candidate vaccine CVnCoV. } \\
\text { Results reported in a preprint }{ }^{43} \text {; industry-funded. }\end{array}$ & $\begin{array}{l}\text { International: } \\
248 / 168 \\
\text { Germany: n.r./ } \\
\text { n.r. }\end{array}$ \\
\hline $\begin{array}{l}\text { ACTIV-3/TICO } \\
\text { (EUCTR2020- } \\
\text { 003278-37-DK) }\end{array}$ & $\begin{array}{l}\text { A platform adaptive trial assessing multiple interventions versus } \\
\text { placebo in hospitalized patients with COVID-19 without end-organ } \\
\text { failure on sustained recovery during a 90-day period. The results } \\
\text { reported on } 314 \text { patients focus on the neutralizing monoclonal } \\
\text { antibody LY-CoV555 when co-administered with remdesivir which did } \\
\text { not demonstrate stat. significant efficacy (OR } 0.85,95 \% \text { CI [0.56; } 1.29] \text {, } \\
\text { p=0.45). } \\
\text { This intervention arm was terminated early for futility following the } \\
\text { data and safety monitoring board recommendation, but the trial is } \\
\text { ongoing. } \\
\text { Results reported in a peer review publication }{ }^{44} \text {; industry-funded. }\end{array}$ & $\begin{array}{l}\text { International: } \\
\text { n.r./n.r. * } \\
\text { Germany: 0/n.r. }\end{array}$ \\
\hline $\begin{array}{l}\text { CYCOV } \\
\text { (NCT04324528) }\end{array}$ & $\begin{array}{l}\text { Cytokine removal therapy in inpatients requiring veno-venous ECMO } \\
\text { on interleukin- } 6 \text { level on serum interleukin- } 6 \text { (IL-6) concentration } 72 \mathrm{~h} \\
\text { after initiation of ECMO. Adjusted mean log IL- } 6 \text { concentrations after } 72 \\
\text { h were } 0.30 \text { higher in the cytokine adsorption group ( } 95 \% \mathrm{CI}-0.70 \text { to } \\
1.30, p=0.54) \text {. In addition, early initiation of cytokine adsorption had a } \\
\text { negative effect on survival. } \\
\text { Results reported in a peer review publication }{ }^{45} \text {; industry-funded. }\end{array}$ & $\begin{array}{l}\text { International: } \\
\text { n.a. } \\
\text { Germany } 34 / 30\end{array}$ \\
\hline $\begin{array}{l}\text { CAPSID } \\
\text { (EUCTR2020- } \\
\text { 001310-38-DE) }\end{array}$ & $\begin{array}{l}\text { Convalescent plasma in inpatients on a composite endpoint of survival } \\
\text { and no longer fulfilling criteria of severe COVID- } 19 \text {. } \\
\text { There was no stat. significant difference with } 43.4 \% \text { of patients in the } \\
\text { convalescent plasma group and } 32.7 \% \text { in the control group reaching } \\
\text { the primary outcome }(p=0.32) \text {. A pre-defined subgroup analysis } \\
\text { showed a significant benefit for convalescent plasma among those who } \\
\text { received a larger amount of neutralizing antibodies. } \\
\text { Results posted as a preprint }{ }^{46} \text {; industry-funded. }\end{array}$ & $\begin{array}{l}\text { International: } \\
\text { n.a. } \\
\text { Germany: } \\
\text { 105/106 }\end{array}$ \\
\hline
\end{tabular}

Abbreviation: $\mathrm{ECMO}=$ extracorporeal membrane oxygenation; $\mathrm{n} . \mathrm{a}$. = not applicable; $\mathrm{n} . \mathrm{r}$. = not reported; stat. = statistically; $\mathrm{CI}=$ confidence interval.

Notes: * Adaptive designs, the target sample size is continuously re-evaluated.

\section{Actual recruitment in Germany}

The median number of planned participants from Germany was 106, while the median recruited was actually 15 participants per trial (IQR, 0 to 44), corresponding to a median proportion of $13.4 \%$ of the Germany-specific target sample size recruited per trial (IQR, 0 to $29.2 \%$, range 0 to $113 \%$ ). This proportion was almost identical (13.6\%) in the 13 trials that announced a completion date by April 2021 and provided recruitment information (Table 2). Two of these 13 (15.4\%) reached their target sample size (i.e., at least 99\%; Figure 1).

From the 65 trials, $11(16.9 \%)$ have not yet been recruiting or, although they had planned to, will never recruit participants in Germany.

The trials with recruitment information from the investigator survey were more often completely conducted in Germany ( $74.1 \%$ vs. $36.8 \%$ partially conducted in Germany), more often publicly funded ( $80 \%$ vs. $34.3 \%$ industry-funded), and more often registered in the first half of 2020 (64.3\% vs. $31.8 \%$ second half of 2020; see extended data $\left.{ }^{8}\right)$.

\section{Trials identified post-hoc}

The search in COVID-evidence in August 2021 identified three additional small trials aiming to include 64 to 130 patients. Two were registered late December 2021, and two have been completed, however none of the results are available. For details see extended data. ${ }^{8}$ 


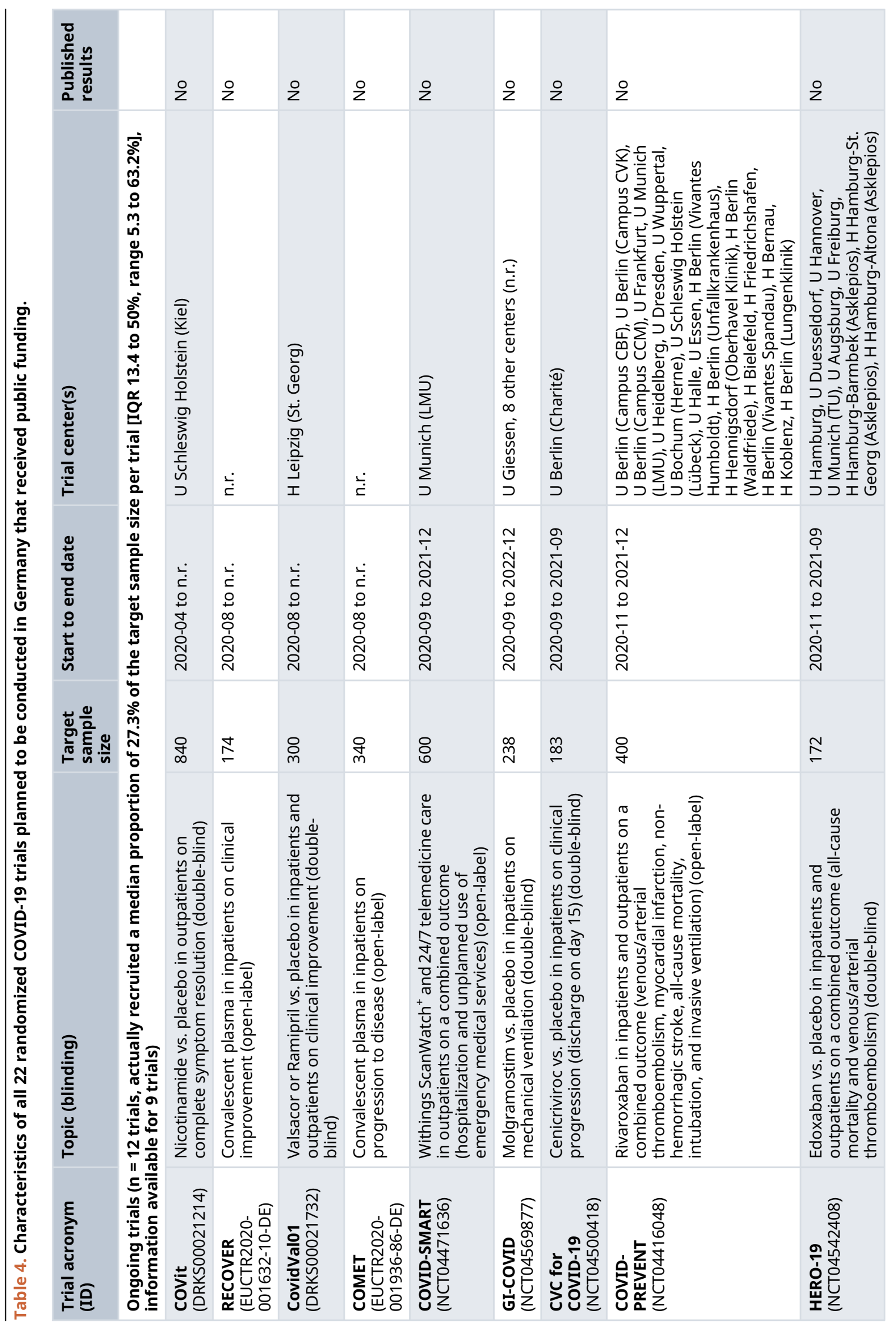




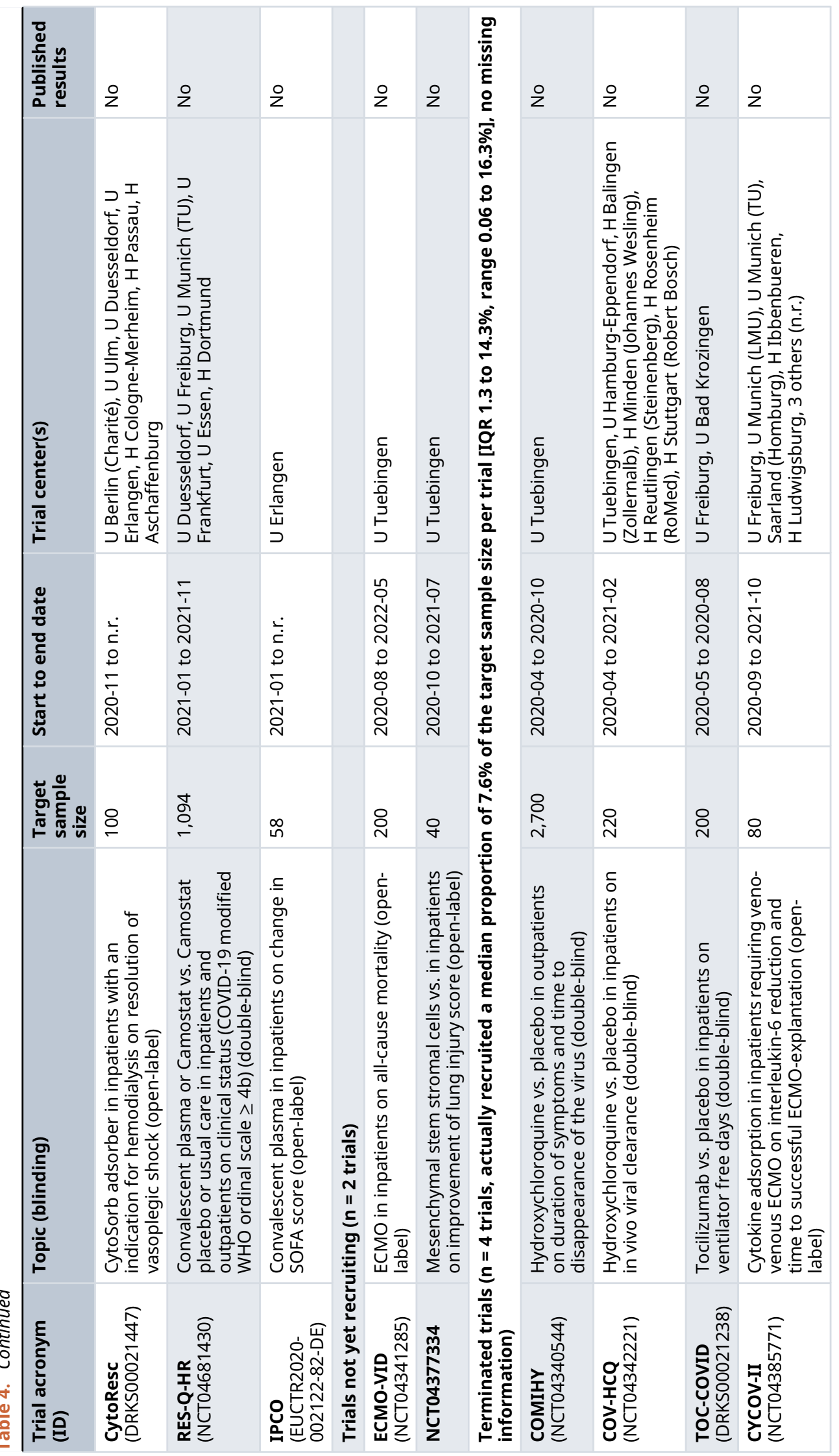




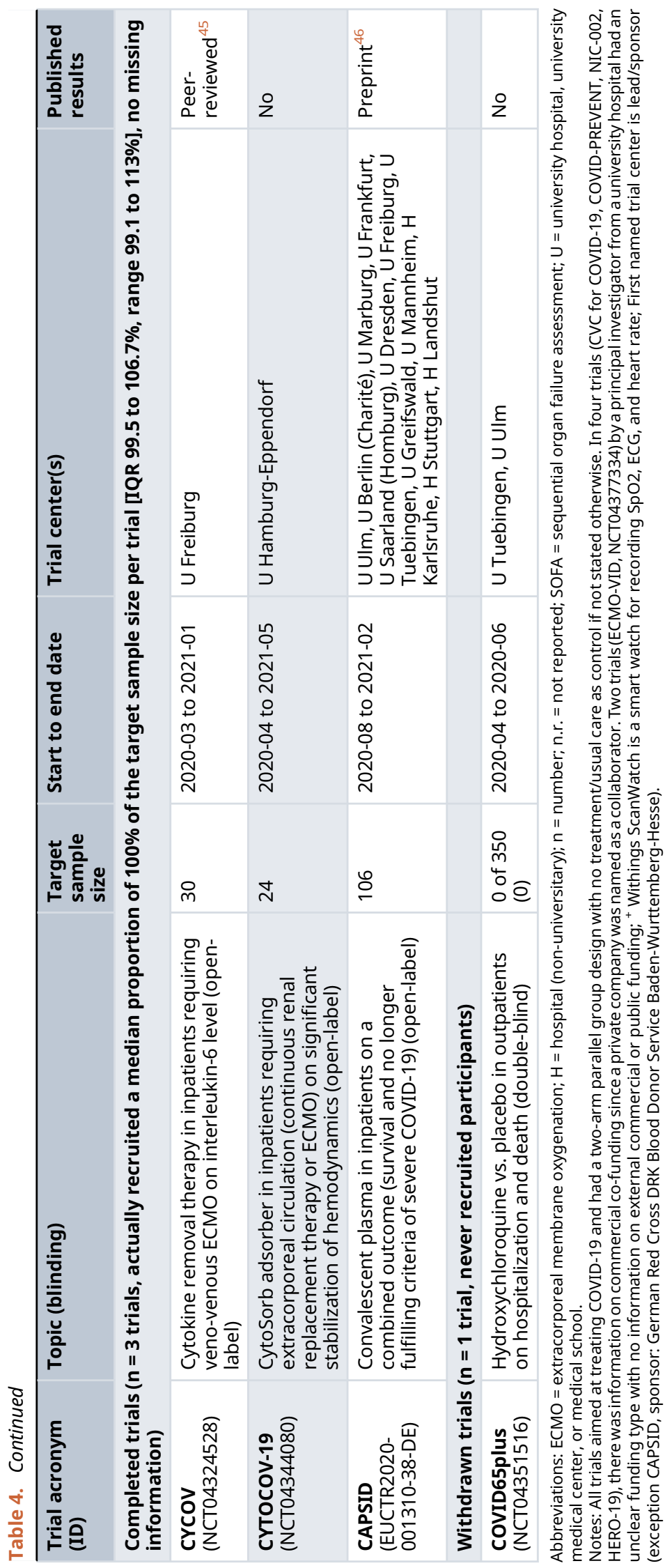




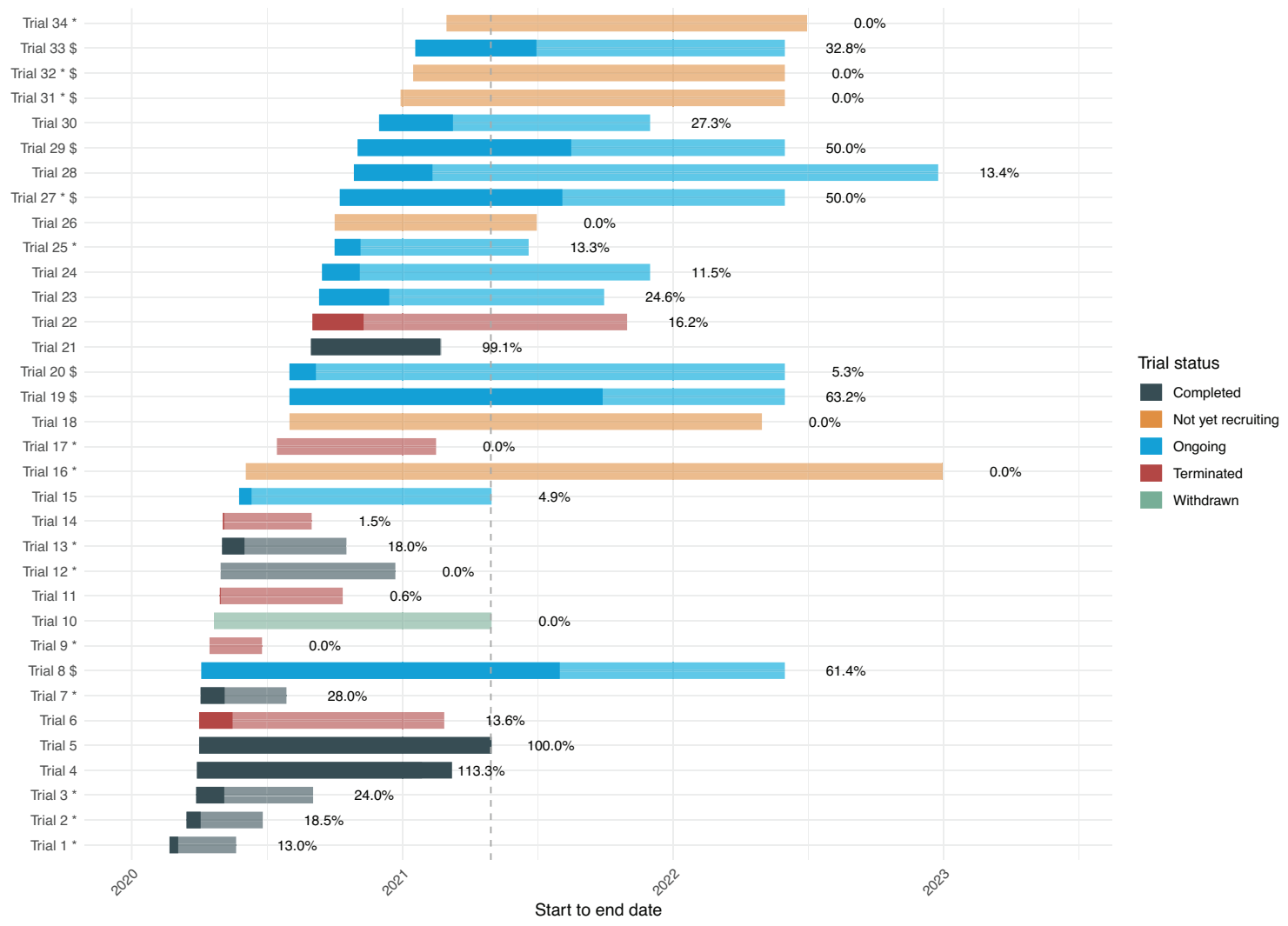

Figure 1. Timeline, status, and actual recruitment for all $\mathbf{3 4}$ trials with recruitment information. Notes: The figure illustrates the length of the trials with their start and end date of conduct, sorted by start date and colored by status (based on trial registration details or investigators' request). The darker part of the bars illustrates the proportion of the target sample size in Germany that was actually recruited within each trial with the corresponding proportion (percentages reported next to the bar). The dashed vertical line corresponds to the timepoint of the recruitment status assessment, April 2021. Trials can be declared as "completed" with or without reaching their target sample size. "Terminated" trials end without reaching their intended goals and started recruiting but are not considered "complete". "Withdrawn" trials will never start or recruit patients. * Trials that were partially conducted in Germany: the proportion of target sample size focus only on German participants and does not reflect the international recruitment accrual; \$ End date was not available and was arbitrarily set at 1 June 2022.

\section{Discussion}

This systematic analysis of the clinical trial research agenda on COVID-19 in Germany showed that from the almost 3,000 trials registered worldwide in 2020, only 65 trials planned to include participants in Germany.

Approximately 20,696 participants from Germany were planned to be included in COVID-19 clinical trials, of which 10,613 patients would be treated for this disease. The typical COVID-19 trial with a German contribution aimed to include 106 persons in Germany, however achieved to recruit a fraction (13.4\%, or 15 persons per trial). This estimate did not change when we considered trials which planned to be completed at the timepoint of our recruitment assessment in April 2021. While precise information was not available for all trials, it can be estimated that under 3,000 individuals have been included in COVID-19 RCTs in Germany (13.4\% of the 20,696 German participants planned in 55 of 65 trials). In trials for COVID-19 treatments, the estimated total participants were approximately $1,500(13.5 \%$ of 10,613 participants in 48 of 56 treatment trials). This is a small fraction of the approximately 155,000 COVID-19 hospitalizations reported during 2020 in Germany. ${ }^{11}$ These data indicate that in Germany about 1 out of 100 hospitalized patients participated in a trial to investigate potential COVID-19 therapies, while in the United Kingdom, 1 out of 6 hospitalized patients for COVID-19 took part in the RECOVERY trial. ${ }^{12}$

It was also unexpected that despite the very prominent and successful position of Germany in research and development of highly effective vaccines, more German participants have not contributed to the overall vaccine research agenda. 
There was a considerable public investment in clinical research for COVID-19. The German Federal Ministry of Education and Research (BMBF) spent 1.6 billion $€$ for research projects related to COVID-19, a large part being allocated to vaccine development. ${ }^{7}$ The RECOVERY trial reported the cost per patient at $£ 250$, corresponding to a total of approximately 1 million Euro for a trial with 3,000 persons. ${ }^{13}$ As illustrated in Figure 1, the planned number of participants in Germany has been reached in three of the completed, and none of the early terminated trials. Moreover, 2 out of the 13 trials that announced a completion date by April 2021 reached their target sample size. The proportions of already recruited participants in the ongoing trials agree with the overall interpretation, and do not exclude delayed recruitment, which is further corroborated by the six not yet recruiting trials. Decisions for early termination may very well indicate reasonable and well-founded strategic decisions to avoid wasting research resources, however it may also reflect recruitment difficulties or other challenges. An overestimation of eligible participants or prejudiced views by recruiters and participants on trial interventions are common reasons for low recruitment. ${ }^{14}$ However, the massive impact of the COVID-19 pandemic on health care systems and clinical research institutions has challenged trial recruitment as well. ${ }^{15,16}$ Most countries do not have the long-established and effective clinical trial infrastructure and academic environments such as the UK, where the feasibility of rapid setup and implementation of massive clinical trials has been impressively demonstrated. The RECOVERY trial was planned in two days, included more than 10,000 patients with the first patient enrolled after nine days, and discovered the first mortality-lowering treatment for COVID-19 in two months. $^{2}$ The highly pragmatic and embedded-in-usual-care study design were major drivers of this unprecedented successful clinical research.

As the reasons that might have led to successful or unsuccessful recruitment in the German trials were not assessed in this study, further research is needed to understand the recruitment challenges, and how they can be mitigated to facilitate recruitment success for clinical trials in Germany in situations where decision-relevant evidence is urgently needed. A careful comparison of the German research environment for clinical trial research with international circumstances seems warranted.

The focus of the trial research in Germany was similar to the worldwide trial landscape with a strong weight on exploring treatment with drugs and biologicals. ${ }^{1}$ Our results indicate that there were no RCTs registered in 2020 assessing strategies to control the pandemic spread, social distancing, or behavioral interventions although those have been strictly applied in Germany. There was also no German contribution with RCTs conducted in nursing homes, kindergarten, childcare, or schools although the role of these settings was under considerable discussion. Conversely, there are international examples of RCTs aiming to determine the best strategies for preventing virus transmission. Many trials in the US, for example, were planned to investigate how tailored programs to increase adherence to preventive measures would affect transmission rates. ${ }^{17-19}$ Another US randomized trial included almost 20 million people to assess how digital information may affect local case rates. ${ }^{20}$ Different testing strategies to ensure safe gatherings at mass events have also been investigated in Spain, ${ }^{21}$ France ${ }^{22}$ and Norway. ${ }^{23}$ In case of facing future pandemics with similar challenges, such research would be highly important to develop evidence-based public health interventions and to improve policymaking in Germany.

This study has several limitations. First, our sample depended on accurate trial registrations and reports in the biomedical literature. We cannot exclude those trials conducted in Germany that have not been identified, for example because they were not registered, the registry data gave no indication of a German contribution, or the registry entry was delayed. Nevertheless, searching the Germany-specific registry DRKS did not yield any additional trials. The use of the most recent version of COVID-evidence in August 2021 resulted in just one more trial not previously captured by the filter, and two additional studies registered very late (28 and 30 December 2020) not previously captured due to time lags in registries. While these three studies are not included in the recruitment analysis, they have similar characteristics to the other trials and would not impact our overall interpretation. Second, although we obtained information for more than half of all included trials in an investigator request, we still had incomplete data on the actual recruitment in Germany with imbalances related to some trial characteristics. For example, we had recruitment information for $34.3 \%$ of the industryfunded trials compared to $80 \%$ of the publicly-funded trials. However, it is unlikely that the other trials have substantially higher recruitment and completion rates, and that missing recruitment information significantly affected our results. Even a five-fold higher recruitment rate in these remaining trials would not change the overall picture: which is that most trials have not been successfully recruited. Finally, the estimation of a target sample size might not be applicable for the few trials with an adaptive design, since sample size (and other methodological trial characteristics) may change over time. Therefore, our analysis related to adaptive designs should be seen contextualized within the trial progress. However, the median reported target sample size for trials with and without adaptive designs was similar.

\section{Conclusions}

The overall German contribution to the worldwide clinical trial research agenda for COVID-19 has been relatively modest. While few excellent examples of successful individual trial recruitment exist, most trials were not able to meet 
their goals and did not deliver the much needed evidence. A close evaluation and international comparison of the challenges and barriers for conducting clinical trials in Germany is urgently needed.

\section{Data availability}

Extended data

Open Science Framework (OSF): COVID-evidence: A living database of trials on interventions for COVID-19/Clinical trial research on COVID-19 in Germany - a systematic analysis.

DOI: https://doi.org/10.17605/OSF.IO/CD6RQ. ${ }^{8}$

The supplement file contains the following extended data:

- Data sources and search strategy

- Email template/Recruitment information request

- Email template/Data confirmation request

- PRISMA flow diagram for trial identification

- Table 1 a. Characteristics of randomized COVID-19 trials planned to be conducted in Germany

- Table 1 b. Trial characteristics and recruitment details

- Characteristics of trials identified post-hoc

Open Science Framework (OSF): COVID-evidence: A living database of trials on interventions for COVID-19.

DOI: https://doi.org/10.17605/OSF.IO/GEHFX. ${ }^{9}$

The project contains the following extended data:

- COVID-evidence protocol

Reporting guideline

Open Science Framework (OSF): PRISMA checklist for 'Clinical trial research on COVID-19 in Germany - a systematic analysis.

DOI: https://doi.org/10.17605/OSF.IO/CD6RQ. ${ }^{8}$

Data are available under the terms of the Creative Commons Zero "No rights reserved" data waiver (CC0 1.0 Public domain dedication)

\section{Author contributions}

JH performed conceptualization, formal analysis, investigation, methodology, project administration, validation, visualization, original draft preparation, and review \& editing of the article. AR and MB conducted investigation, validation, and review \& editing of the article. PD conducted data curation and review \& editing of the article. PJ performed conceptualization, formal analysis, investigation, methodology, project administration, supervision, validation, visualization, original draft preparation, and review \& editing of the article. LGH was involved in conceptualization, funding acquisition, methodology, project administration, resources, supervision, validation, visualization, original draft preparation, and review \& editing of the article.

\section{Ethical approval}

Not required, this article does not contain any personal medical information about any identifiable living individuals. 
1. Janiaud P, Axfors C, van't Hooft J, et al.: The worldwide clinical trial research response to the COVID-19 pandemic - the first 100 days [version 2; peer review: 2 approved]. F1000Res. 2020; 9: 1193. PubMed Abstract | Publisher Full Text | Free Full Text

2. Nuffield Department of Population Health: How to set up a trial in nine days. 2021. Accessed June 06, 2021.

Reference Source

3. REMAP-CAP:REMAP-CAP response to the COVID-19 pandemic 2020 Accessed May 31, 2021

Reference Source

4. World Health Organization: "Solidarity" clinical trial for COVID-19 treatments 2020. Accessed May 31, 2021.

Reference Source

5. REMAP-CAP: REMAP-CAP Trial: Participating sites 2021. Accessed May 31, 2021.

Reference Source

6. ClinicalTrials.gov: An International Randomized Trial of Additional Treatments for COVID-19 in Hospitalized Patients Who Are All Receiving the Local Standard of Care - WHOSOLIDARITY-GERMANY: NCT04575064 2020. Accessed May 31, 2021.

Reference Source

7. Knapp 1,6 Milliarden Euro für Coronaforschung. Deutsches Ärzteblatt. 20 April 2021. Accessed May 28, 2021.

Reference Source

8. Hirt J, Rasadurai A, Briel M, et al.: Clinical trial research on COVID19 in Germany - a systematic analysis. 2021. Accessed August 18,2021

Publisher Full Text

9. Janiaud P, Axfors C, Saccilotto R, et al.: CoviD-evidence: a living database of trials on interventions for COVID-19. 2021. Accessed May 31, 2021

Reference Source

10. COVID-evidence Database: Planned, ongoing and completed trials to treat and prevent COVID-19. 2021. Accessed July 27, 2021. Reference Source

11. Augurzky B, Busse R, Alexander $\mathrm{H}$, et al.: Analysen zum Leistungsgeschehen der Krankenhäuser und zur Ausgleichspauschale in der Corona-Krise: Ergebnisse für den Zeitraum Januar bis Dezember 2020 Im Auftrag des Bundesministeriums für Gesundheit. 2021. Accessed July 15,2021 Reference Source

12. Kupferschmidt K: One U.K. trial is transforming COVID-19 treatment. Why haven't others delivered more results? 2020. Accessed June 06, 2021

Reference Source

13. Horby P: RECOVERY has shown that it is possible to massively accelerate medical advances and massively decrease costs. Estimated cost of $£ 250$ per patient enrolled - a fraction of other clinical trials 2021. Accessed June 23, 2021.

Reference Source

14. Briel $\mathrm{M}$, Olu $\mathrm{KK}$, von Elm E, et al.: A systematic review of discontinued trials suggested that most reasons for recruitment failure were preventable. J Clin Epidemiol. 2016. Article in Press.

PubMed Abstract | Publisher Full Text

15. Burns JE, Carlin FE: Experience of conducting clinical trials of investigational medicinal products during a respiratory virus pandemic: Lessons learnt from COVID-19. Clin Trials. 2021; 18(2): 260-262.

PubMed Abstract | Publisher Full Text

16. Vissers MFJM, Cohen AF, van Gerven JMA, et al.: The impact of the global COVID-19 pandemic on the conduct of clinical trials: Return to normalcy by considering the practical impact of a structured ethical analysis. BrJ Clin Pharmacol. 2021; 87(3): 837-44. PubMed Abstract | Publisher Full Text

17. Massachusetts General Hospital: Best Practices to Prevent COVID19 Illness in Staff and People With Serious Mental Illness and Developmental Disabilities in Congregate Living Settings: NCT04726371. 2021. Accessed July 23, 2021 Reference Source

18. Milton SHershey Medical Center: COVID-19 Project ECHO for Nursing Homes: A Patient-centered, Randomized-controlled Trial to Implement Infection Control and Quality of Life Best Practice: NCT04499391 2021. Accessed July 23, 2021. Reference Source

19. Washington University School of Medicine: Supporting the Health and Well-being of Children With Intellectual and Developmental Disability During COVID-19 Pandemic:
NCT04565509 2020. Accessed July 23, 2021

Reference Source

20. Breza E, Stanford FC, Alsan M, et al.: Doctors' and Nurses' Social Media Ads Reduced Holiday Travel and COVID-19 infections: A cluster randomized controlled trial in 13 States. Preprint; 2021 (accessed 29 Jul 2021)

Publisher Full Tex

21. Fundación FLS de Lucha Contra el Sida: Risk of Infection of Severe Acute Respiratory Syndrome Coronavirus-2 (SARS-CoV-2), COVID-19, in a Massive Musical Show With Transmission Prevention Measures: NCT04668625. Accessed June 29, 2021. 2021.

Reference Source

22. ANRS Emerging Infectious Diseases: Protective Measures Against SARS-CoV-2 Contamination of Young Healthy Volunteers During a Concert of Actual Music (CONCERTSAFE): NCT04868942. Accessed June 29, 2021. 2021. Reference Source

23. Norwegian Institute of Public Health: Antigen Rapid Test Screening to Prevent SARS-CoV-2 Transmission (COVID-19) at Mass Gathering Events.: NCT04898127. 2021. Accessed June 28, 2021 Reference Source

24. Goldman JD, Lye DCB, Hui DS, et al.: Remdesivir for $\mathbf{5}$ or $\mathbf{1 0}$ Days in Patients with Severe Covid-19. N Engl J Med. 2020; 383(19): 1827-1837. 1827-1837.

PubMed Abstract | Publisher Full Text | Free Full Text

25. Spinner CD, Gottlieb RL, et al.: Effect of Remdesivir vs Standard Care on Clinical Status at 11 Days in Patients With Moderate COVID-19: A Randomized Clinical Trial. JAMA. 2020; 324(11): 1048-1057.

PubMed Abstract | Publisher Full Text | Free Full Text

26. Beigel JH, Tomashek KM, Dodd LE, et al.: Remdesivir for the Treatment of Covid-19 - Final Report. N EnglJ Med. 2020; 383(19): 1813-1826.

PubMed Abstract | Publisher Full Text | Free Full Text

27. Vlaar APJ, de Bruin S, Busch M, et al.: Anti-C5a antibody IFX-1 (vilobelimab) treatment versus best supportive care for patients with severe COVID-19 (PANAMO): an exploratory, open-label, phase 2 randomised controlled trial. Lancet Rheumatol. 2020; 2(12): e764-e773.

PubMed Abstract | Publisher Full Text | Free Full Text

28. Rosas IO, Bräu N, Waters M, et al.: Tocilizumab in Hospitalized Patients with Severe Covid-19 Pneumonia. N Engl J Med. 2021; 384(16): 1503-1516.

Publisher Full Text

29. Lescure F-X, Honda H, Fowler RA, et al.: Sarilumab in patients admitted to hospital with severe or critical COVID-19: a randomised, double-blind, placebo-controlled, phase 3 trial. Lancet Respir Med. 2021; 9(5): 522-532. Publisher Full Text

30. Axfors C, Schmitt AM, Janiaud P, et al.: Mortality outcomes with hydroxychloroquine and chloroquine in COVID-19 from an international collaborative meta-analysis of randomized trials. Nat Commun. 2021; 12: 2349.

PubMed Abstract | Publisher Full Text | Free Full Text

31. Angus DC, Derde L, Al-Beidh F, et al.: Effect of Hydrocortisone on Mortality and Organ Support in Patients With Severe COVID-19: The REMAP-CAP COVID-19 Corticosteroid Domain Randomized Clinical Trial. JAMA. 2020; 324(13): 1317-1329. PubMed Abstract | Publisher Full Text | Free Full Text

32. Gordon AC, Mouncey PR, Al-Beidh F, et al.: Interleukin-6 Receptor Antagonists in Critically Ill Patients with Covid-19. N Engl/ Med. 2021; 384(16): 1491-1502. Publisher Full Text

33. Zarychanski R: Therapeutic Anticoagulation in Critically Il Patients with Covid-19 - Preliminary Report: The REMAP-CAP, ACTIV-4a, and ATTACC Investigators. Preprint 2021. Accessed July 12, 2021. Publisher Full Text

34. REMAP-CAP: Equivalency Of Tocilizumab And Sarilumab 2021. Accessed May 28, 2021

Reference Source

35. REMAP-CAP. PRESS RELEASE: International Trial of SARS-CoV-2 Convalescent Plasma Pauses Enrollment of Critically III COVID19 Patients: PRESS RELEASE REMAP-CAP 2021. Accessed May 28, 2021. Reference Source

36. Novartis: Novartis provides update on RUXCOVID study of ruxolitinib for hospitalized patients with COVID-19 2020. 
Accessed May 28, 2021.

Reference Source

37. Mulligan MJ, Lyke KE, Kitchin N, et al.: Phase I/II study of COVID-19 RNA vaccine BNT162b1 in adults. Nature. 2020 586(7830): 589-593.

PubMed Abstract | Publisher Full Text

38. Polack FP, Thomas SJ, Kitchin N, et al.: Safety and Efficacy of the BNT162b2 mRNA Covid-19 Vaccine. N EnglJ Med. 2020; 383(27): 2603-2615.

Publisher Full Text

39. Walsh EE, Frenck RW, Falsey AR, et al.: Safety and Immunogenicity of Two RNA-Based Covid-19 Vaccine Candidates. N EnglJ Med. 2020; 383(25): 2439-2450.

PubMed Abstract | Publisher Full Text | Free Full Text

40. Abivax: Abivax Follows DSMB Recommendation to Stop the Phase 2b/3 miR-AGE Covid-19 Clinical Trial Due to Lack of Efficacy 2021 Reference Source

41. Novartis: Novartis provides update on CAN-COVID trial in hospitalized patients with COVID-19 pneumonia and cytokine release syndrome (CRS) 2020. Accessed May 28, 2021.

Reference Sourc
42. Eli Lilly and Company: Lilly and Incyte announce results from the Phase 3 COV-BARRIER study of baricitinib in hospitalized COVID19 patients. 2021. Accessed May 28, 2021. Reference Source

43. Kremsner $P$, Mann $P$, Bosch J, et al.: Phase 1 Assessment of the Safety and Immunogenicity of an mRNA- Lipid Nanoparticle Vaccine Candidate Against SARS-CoV-2 in Human Volunteers: Preprint. 2020. Accessed July 12, 2021. Publisher Full Text

44. Lundgren JD, Grund B, Barkauskas CE, et al:: A Neutralizing Monoclonal Antibody for Hospitalized Patients with Covid-19. N EnglJ Med. 2021; 384(10): 905-914. Publisher Full Text

45. Supady A, Weber E, Rieder M, et al.: Cytokine adsorption in patients with severe COVID-19 pneumonia requiring extracorporeal membrane oxygenation (CYCOV): a single centre, open-label, randomised, controlled trial. Lancet Respir Med. 2021. Article in Press. Publisher Full Text

46. Körper S, Weiss M, Zickler D, et al.: High Dose Convalescent Plasma in COVID-19: Results from the Randomized Trial CAPSID: Preprint. 2021. Accessed July 12, 2021.

Publisher Full Text 


\section{Open Peer Review}

\section{Current Peer Review Status:}

\section{Version 1}

Reviewer Report 11 March 2022

https://doi.org/10.5256/f1000research.59126.r124218

(C) 2022 De Soyza A. This is an open access peer review report distributed under the terms of the Creative Commons Attribution License, which permits unrestricted use, distribution, and reproduction in any medium, provided the original work is properly cited.

\section{Anthony De Soyza}

${ }^{1}$ Population Health Science Institute, NIHR Newcastle Biomedical Research Centre, Newcastle University, Newcastle, UK

2 Comprehensive Research Network Respiratory Disorders Group, National Institute for Health Research, Newcastle, UK

This is an interesting and candid report by Hirt, Hemkens and colleagues highlighting limited successes in recruitment into COVID-19 research during the specified time using trial registrations in 2020 in Germany.

It highlights that recruitment was rarely satisfactory with a median rate of recruitment vs target of $\sim 13 \%$. The median number of planned participants from Germany was 106, while the median recruited was actually 15 participants per trial (IQR, 0 to 44). The manuscript displays data on the recruitment rates of studies identified by multiple methods and covers a broad range of COVID facing approaches including devices (ECMO), anti virals and anti- inflammatory therapies.

The work has many commendable features but there are some limitations that could be more fully discussed.

Firstly the registration period may not relate to actual study opening. It is therefore unclear how many studies were impacted by either slow start up and/or rapid closure. The hydroxychloroquine studies noted, for example, may well be explained by the rapid success of RECOVERY reporting lack of benefit meaning early closure. These data may be included within the manuscript but are not easy to identify - some of the explanatory text is more identifiable in this matter in the discussion.

The poor recruitment and attempts to understand why is important as solutions to resolving poor recruitment within a pandemic are complex. The UK experience note din the discussion had a number of factors contributing to "success" ranging from "infrastructure "commented upon by the authors. This relates to an expectation research is part of normal clinical practice and there is specific funding into most organisations to deliver upon this via in England the National Institute 
for Health Research (NIHR) Comprehensive research network (CRN).

What is not well described in this paper is the differences in approvals/ site selection/ national imperatives and process for dealing with competing studies in Germany. The trials infrastructure in Germany is not discussed (who decides which sites take on which studies and what resource if any is funded nationally? What is the incentive to do pragmatic non-commercial studies vs fee paying low volume complex industry studies? One cannot therefore develop an understanding of why there were such differences in experiences within Germany (some studies did hit targets as reported herein) and why there are differences between countries.

These all need to be discussed/ dissected to understand how coordination of research efforts was/ was not a root cause of the poor recruitment as opposed to lack of staff capacity/selecting small volume high intensity trials vs low intensity pragmatic trials.

The authors may wish to clarify the tables/ figures where figure 1 notes trials 1-34 but does not directly link them to the preceding tables. It would be useful to understand why some of the studies hitting target were different to those not.

Other issues relate to ongoing open studies that are limited to Germany only - there can be investigator led reticence to close down failing studies - if these studies are still failing to recruit and are closed down then recruitment success to studies overall will fall further as a \% of studies hitting target. This limitation should be noted

The authors may wish to note Cunliffe et al (2020) How achievable are COVID-19 clinical trial recruitment targets? A UK observational cohort study and trials registry analysis - PubMed (nih.gov) an analysis of clinical trials feasibility in the UK showing that there was likely an over commitment within the UK that needed national coordination to prioritise the most important studies. ${ }^{1}$

The UK National Institute for Health research (NIHR) developed and rapidly implemented an Urgent Public health (UPH) Panel. It pulled in very broad expertise and linked with governmental advisory panels from therapeutics and vaccines plus trials infrastructure delivery \& methodology experts to help focus efforts on selecting and then delivering studies. This huge body of work involved reviewing 1000s of studies thrice weekly for much of 2020 to drill down a focus; 95 were listed of which the initial 5 included RECOVERY and PRINCIPLE studies (listed from Jan 2020-Mach 2020). See Urgent Public Health COVID-19 Studies | NIHR.

There are very many challenges in delivering research successfully even more so in the middle of a pandemic. The authors should be commended on writing the first chapter in Germanys' book on this. The authors identify the success was below ideal. The challenges are now to identify where improvements can be made to ensure in the future, Germany can harness the potential to deliver research more rapidly.

\section{References}

1. Cunniffe N, Gunter S, Brown M, Burge S, et al.: How achievable are COVID-19 clinical trial recruitment targets? A UK observational cohort study and trials registry analysis. BMJ Open. 2020; 10 (10). Publisher Full Text 
Is the work clearly and accurately presented and does it cite the current literature? Partly

Is the study design appropriate and is the work technically sound?

Partly

Are sufficient details of methods and analysis provided to allow replication by others? Yes

If applicable, is the statistical analysis and its interpretation appropriate? Partly

Are all the source data underlying the results available to ensure full reproducibility? Partly

Are the conclusions drawn adequately supported by the results? Partly

Competing Interests: I am employed by the UK NIHR as National Specialty Lead for the Comprehensive Research Network Respiratory disorders group (NIHR-CRN). I have received funding from a variety of pharmaceutical companies as grant support unrelated to this work. Additionally my funding institution receives fees for site activities for clinical trials I participate in as a Principal / Coordinating Investigator

Reviewer Expertise: Research background Respiratory medicine, Clinical Trials, COVID 19,

I confirm that I have read this submission and believe that I have an appropriate level of expertise to confirm that it is of an acceptable scientific standard.

The benefits of publishing with F1000Research:

- Your article is published within days, with no editorial bias

- You can publish traditional articles, null/negative results, case reports, data notes and more

- The peer review process is transparent and collaborative

- Your article is indexed in PubMed after passing peer review

- Dedicated customer support at every stage

For pre-submission enquiries, contact research@f1000.com 